\title{
Impact of ventilator-associated
}

\section{pneumonia on mortality and epidemiological features of patients with secondary peritonitis}

\author{
María Heredia-Rodríguez ${ }^{1,2^{*}}$, María Teresa Peláez ${ }^{1 *}$, Inmaculada Fierro ${ }^{3}$, Esther Gómez-Sánchez ${ }^{1,2}$, \\ Estefanía Gómez-Pesquera 1,2, Mario Lorenzo 1,2 , F. Javier Álvarez-González ${ }^{3}$, Juan Bustamante-Munguira4, \\ José María Eiros²,5, Jesús F. Bermejo-Martin²,6, José I. Gómez-Herreras ${ }^{1,2}$ and Eduardo Tamayo ${ }^{1,2}$
}

\begin{abstract}
Background: Despite the significant impact of nosocomial infections on the morbidity and mortality of patients staying in the intensive care unit (ICU), no study over the past 20 years has focused specifically on VAP following secondary peritonitis. The objective of the present study was to determine in-hospital mortality and epidemiological features attributed to ventilator-associated pneumonia (VAP) following secondary peritonitis.

Methods: Prospective observational study involved 418 consecutive patients admitted in the ICU. Univariate and multivariate analyses were performed to identify risk factors associated with mortality and development of VAP.

Results: The incidence of VAP following secondary peritonitis was $9.6 \%$. Risk factors associated with the development of VAP were hospital-acquired peritonitis, requiring $>48 \mathrm{~h}$ of mechanical ventilation, and SOFA score. The onset of VAP was late in majority of patients. VAP was developed about 16.8 days after the initiation of the peritonitis. Etiological microorganisms responsible for the peritonitis were different than for VAP. The 90-day in-hospital mortality rate was $47.5 \%$ of VAP patients. Independent factors associated with 30- to 90-day in-hospital mortality were VAP and SOFA.
\end{abstract}

Conclusions: In light of the impact on morbidity and mortality in the ICU, more attention should be given to the concurrent features among VAP and secondary peritonitis.

\section{Background}

Intra-abdominal infections (IAIs) are one of the most important causes of mortality in the intensive care unit (ICU) [1]. Secondary peritonitis constitutes $80-90 \%$ of cases of IAIs and is originated from the microbiological infection of the gastrointestinal tract by the perforation of hollow organs, ischemia, malignancy, and perioperative complications (anastomotic leakage, intraoperative contamination) $[2,3]$. Secondary peritonitis can be classified in community-acquired and hospital-acquired, this

\footnotetext{
*Correspondence: maria_her_05@hotmail.com;

mteresapelaez@gmail.com

${ }^{1}$ Anaesthesiology and Surgical Critical Care Department, Hospital Clínico

Universitario de Valladolid, Avenida Ramón y Cajal, 3, 47005 Valladolid,

Spain

Full list of author information is available at the end of the article
}

latter associated with microorganisms presenting antibiotic resistance [2]. Mortality rate due to secondary peritonitis ranges approximately between 10 and $20 \%$ [4-6]. During the management, the clinical outcome of the patient may be critically compromised by the development of nosocomial infections [7]. Ventilator-associated pneumonia (VAP) is a type of hospital-acquired pneumonia that is developed after at least $48 \mathrm{~h}$ of the patient's intubation [8]. VAP is the most frequent of the nosocomial infections occurring in the ICU, affecting to 9-27 \% of all intubated patients [9]. The VAP is associated with an increased length of hospital stay, of about 4-13 days, and hospital costs [10-13]. In our knowledge, there are only in the literature three studies analyzing specifically clinical and epidemiological aspects of the development of VAP following secondary peritonitis. The first 
one was a retrospective study of 1982, which reported clinical outcomes of 143 patients with intra-abdominal abscesses, and revealing an incidence of VAP of $28.7 \%$ of the patients, and a mortality rate attributed to VAP of $65.9 \%$ [14]. The second one was a prospective study published in 1991 comparing clinical outcomes between nosocomial pneumonia and recurrent IAI [15]. The incidence of VAP was $19.7 \%$ of cases, and the mortality rates were $53 \%$ for the group of patients with pneumonia and no recurrent IAI, and $75 \%$ of those with both conditions. Finally, the third study, of 2006, included retrospectively medical records from 618,495 patients undergoing intraabdominal surgery [16]. From them, 13,292 patients developed subsequently pneumonia, and the mortality rate was of $10.7 \%$.

Although there are extensive studies analyzing secondary IAIs or VAP in the ICU, in our knowledge, studies focusing specifically on VAP following secondary peritonitis are scarce and date mainly from two decades ago. Furthermore, there are some issues that remain being characterized, such as the lapse time between the starting of the peritonitis and VAP onset, and whether or not the etiologic agents responsible for IAIs are the same that for VAP, which is critical for the selection of the empirical antibiotic therapy. Early VAP onset has been associated with better prognosis, while the late one has the highest mortality rates and is often associated with multidrugresistant microorganisms [8]. Our working hypothesis is that pneumonia increases the mortality in patients developing peritonitis. Therefore, the objective of the study was to determine in-hospital mortality and epidemiological features attributed to VAP following secondary peritonitis.

\section{Methods}

This prospective observational study involved consecutive patients admitted in the ICU of the clinical university hospital of Valladolid between May 2008 and May 2015 for the management of a secondary peritonitis. All patients, or family members, signed the written consent form to participate in the study. The collection of respiratory and blood samples, for microbiological examinations, was required for the inclusion in the study. Patients presenting primary peritonitis or those who refused to sign the consent form were excluded from the study. One of the investigators made daily rounds in the ICU to identify eligible patients and determine the onset of VAP. Because of the observational nature of the study, investigators did not interact with ICU treating physicians for the diagnosis or management of VAP. To test our working hypothesis, the primary endpoint was to evaluate whether or not VAP patients had a higher mortality rate than non-VAP patients. Secondary endpoints included the identification of variables potentially associated with in-hospital mortality and with the development of VAP. Procedures were performed in accordance with guidelines established by the hospital's ethics committee and the Declaration of Helsinki.

\section{Surgical procedures and microbiological management}

The surgery was performed by an experienced and trained team following the guidelines for the treatment of complicated IAIs [17]. A laparoscopy or laparotomy was performed taking into account the diagnosis and the preference of the surgeon. Peritoneal fluid was sampled to detect microbiological and mycological activity. The empirical antimicrobial therapy was started as soon as possible and consisted in the administration of amoxicillin/clavulanic acid or meropenem plus linezolid if community-acquired or hospital-acquired peritonitis, respectively. Treatment against yeast infection was only considered in the case of organ failure. Ranitidine (50 mg intravenously every $12 \mathrm{~h}$ ) was administered for gastric protection within the first $24 \mathrm{~h}$ of admission in the ICU. Mouthwashes with chlorhexidine were carried out twice a day [18]. The adequacy of source control was confirmed by specialists in the ICU. The empirical antibiotic treatment for VAP was based on identifying the most common pathogens associated with VAP in the ICU, following international guidelines, including the initial empirical treatment of methicillin-resistant $\mathrm{S}$. aureus with linezolid or teicoplanin and of $P$. aeruginosa with at least one of the following antibiotics: imipenem, cefepime, or piperacillin-tazobactam, in association with amikacin or ciprofloxacin [19].

\section{Diagnosis of VAP}

According to the definition of the Centers for Disease Control and Prevention, VAP was diagnosed upon the presence of new and/or progressive pulmonary infiltrates on a chest radiograph plus 2 or more of the following criteria: fever $\left(\geq 38.5^{\circ} \mathrm{C}\right)$ or hypothermia $\left(<36{ }^{\circ} \mathrm{C}\right)$, leukocytosis $\left(\geq 12 \times 10^{9} / \mathrm{L}\right)$, positive pleural fluid culture, purulent tracheobronchial secretions, or a reduction in $\mathrm{PaO}_{2} / \mathrm{FIO}_{2}$ of at least $15 \%$ in the previous $48 \mathrm{~h}$, a cavitating infiltrate, and/or evidence of bronchiolitis, neutrophilic alveolitis, and consolidation [20, 21]. The diagnosis also included those patients with a Pugin score greater than 6 [22]. The confirmation of the diagnosis included the isolation of at least one pathogenic microorganism in significant bacterial counts, i.e., $\geq 10^{3}$ colonyforming units $(\mathrm{CFU}) / \mathrm{mL}$ for protected specimen brush, $\geq 10^{4} \mathrm{CFU} / \mathrm{mL}$ in case of bronchoalveolar lavage, and $\geq 10^{5} \mathrm{CFU} / \mathrm{mL}$ for endotracheal aspiration. These cutoffs were not modified in patients receiving antimicrobial therapy at the time of VAP diagnosis. Coagulase-negative 
Staphylococcus, Corynebacterium spp., Candida spp., Viridans group streptococci, and Neisseria spp. were no considered pathogenic microorganisms. Special attention was given to species isolated from both peritoneal fluid and lungs.

\section{Outcome variables and statistical analysis}

In-hospital mortality (at 30 days, 30-90 days, and 90 days) was differentiated from caused by the severity of the peritonitis or intraoperative and postoperative events. Patients were evaluated for VAP during mechanical ventilation and within $48 \mathrm{~h}$ after extubation. Hospital-acquired infection was defined when occurred $\geq 48 \mathrm{~h}$ after admission. Early or late VAP onset was established depending on whether VAP was developed before or later the 4th day since the initiation of the peritonitis and the mechanical ventilation. Regarding the results of the antibiogram, the treatment was classified as adequate or inadequate. Multidrug resistance was considered when species showed resistance to at least three groups of antibiotics. Categorical variables were expressed as absolute and relative (\%) frequencies, whereas continuous ones as the median and the standard deviation (SD) or the median and the interquartile range (IQR). Differences between groups were compared by using the $t$ test, with continuous variables, and by Chi-square test or Fisher's exact test, with categorical ones. A univariate analysis, classifying patients in survivors and nonsurvivors, was also carried out to identify potential demographic and clinical factors associated with in-hospital mortality. Kaplan-Meier analysis was performed to compare overall survival regarding the development of VAP. Stepwise logistic regression analyses were performed to identify factors associated with in-hospital mortality and with the development of VAP (odds ratio, OR, and $95 \%$ confidence interval, $95 \% \mathrm{CI}$ ). Independent variables introduced in the models were carefully selected to avoid confounding effects. The statistical significance was established for $p \leq 0.05$. All statistical procedures were performed with SPSS 19.0 software.

\section{Results}

\section{Clinical and microbiological characteristics of patients}

From a total of 418 patients presenting secondary peritonitis, 40 subsequently did develop VAP (9.6\%) and 378 did not (90.4\%; Table 1). The mean lapse time between the starting of the secondary peritonitis and the development of VAP was $16.8 \pm 15.1$ days (community-acquired $14.6 \pm 14.5$ days and hospital-acquired $21.8 \pm 15.7$ days). The VAP onset was early in 12 patients (30.0\%) and late in $28(70.0 \% ; p<0.001)$. The mean age of patients was $71.1 \pm 11.0$ years for those with VAP and $70.0 \pm 13.3$ years for those without VAP. Septic shock was higher in VAP patients $(82.5 \%)$ than non-VAP (61.4\%), whereas severe sepsis was opposite, 17.5 versus $38.6 \%$ of patients, respectively. The infection was mainly hospital-acquired (70.0 \%) in VAP patients, whereas community-acquired (52.1\%) in non-VAP. The main cause of peritonitis was bowel perforation in both groups (47.5 vs $43.6 \%$, respectively). Colon/rectum (50.0 vs $40.7 \%$ ) and small bowel (17.5 vs $19.0 \%$ ) were the most frequent locations of the peritonitis. The acute physiology and chronic health evaluation II (APACHE II) score and the SepsisRelated Organ Failure Assessment (SOFA) score were significantly higher $(p=0.007$ and $p<0.001)$ in VAP patients $(15.95 \pm 4.29$ and $8.10 \pm 2.50)$ than in non-VAP (13.65 \pm 5.16 and $6.22 \pm 2.46$, respectively). A significantly $(p<0.001)$ higher number of VAP patients $(62.5 \%)$ received low-dose steroid therapy than non-VAP patients (25.7\%). VAP patients required significantly $(p<0.001)$ more days of mechanical ventilation $(8.91 \pm 14.49$ days $)$ than non-VAP $(2.61 \pm 6.19$ days). More than $48 \mathrm{~h}$ of mechanical ventilation was required in a higher number of VAP patients (47.5\%) than in non-VAP (20.4\%; $p<0.001)$. The stay in the ICU and the hospital were significantly longer $(p<0.001)$ in VAP patients (median 9.0 days; IQR 7.0-30.0 days; and median 45.0 days; IQR 29.0-61.0 days, respectively) than in non-VAP (median 3.0 days; IQR 1.0-7.0 days; and median 20.0 days; IQR 11.0-34.0 days, respectively; Table 1 ). The most frequent species isolated from lungs of VAP patients were Acinetobacter spp. (45.0\% of patients), Klebsiella spp. (17.5\%), and $P$. aeruginosa (17.5\%) and from their peritoneal fluid were Enterococcus spp. (37.5\%), E. coli (35.0\%), Klebsiella spp. (25.0\%), and anaerobes (25.0\%; Table 2). All microorganisms given in Table 2 are associated with VAP. In lungs from non-VAP patients, the main species isolated were anaerobes ( $0.3 \%$ of patients) and from their peritoneal fluid were $E$. coli $(28.6 \%)$, anaerobes $(27.5 \%)$, and Enterococcus spp. (24.1\%). Only three patients presented the same species in the peritoneal fluid and in lungs (two patients with Klebsiella spp. and one with $P$. aeruginosa; $p<0.001$ ). VAP had a polymicrobial origin in four patients. None of the patients showed more than one VAP episode. Multidrug-resistant species were isolated from 25 VAP patients $(62.5 \% ; p=0.02)$. Regarding the antibiogram, the antibiotic treatment was therefore adequate in 22 VAP patients $(55.0 \%$; $p=0.37)$.

\section{Relationship between secondary peritonitis, pneumonia, and mortality}

Mortality at 30 days was not different between groups and however at 90 days was significantly higher $(p=0.008)$ in VAP patients $(45.0 \%)$ than in non-VAP (5.8\%). Kaplan-Meier survival analysis revealed that the percentage of survival was different between VAP and 
Table 1 Demographic and clinical characteristics $24 \mathrm{~h}$ after the admission in the ICU in patients presenting secondary peritonitis regarding the subsequent development of ventilator-associated pneumonia

\begin{tabular}{|c|c|c|c|}
\hline & VAP patients $(n=40)$ & Non-VAP patients $(n=378)$ & $P$ value \\
\hline Age (mean years $\pm S D$ ) & $71.1 \pm 11.0$ & $70.0 \pm 13.3$ & 0.61 \\
\hline Sex male $[n(\%)]$ & $31(77.5)$ & $217(57.4)$ & 0.014 \\
\hline \multicolumn{4}{|l|}{ Comorbidities [n (\%)] } \\
\hline Diabetes mellitus & $33(82.5)$ & $283(74.3)$ & 0.02 \\
\hline Hypertension & $21(52.5)$ & $194(51.3)$ & 0.81 \\
\hline Malignant neoplasm & $16(40.0)$ & $168(44.4)$ & 0.63 \\
\hline Obesity & $5(12.5)$ & $52(13.8)$ & 0.83 \\
\hline Chronic renal failure & $5(12.5)$ & $34(9.0)$ & 0.46 \\
\hline Immunosuppression & $1(2.5)$ & $13(3.4)$ & \\
\hline Liver disease & $2(5.0)$ & $11(2.9)$ & 0.46 \\
\hline Acute renal failure, dialysis & $2(5.0)$ & $7(1.9)$ & \\
\hline Postoperative status [n (\%)] & & & 0.001 \\
\hline Septic shock & $33(82.5)$ & $232(61.4)$ & \\
\hline Severe sepsis & $7(17.5)$ & $146(38.6)$ & \\
\hline Type of infection [n (\%)] & & & 0.007 \\
\hline Community-acquired & $12(30.0)$ & $181(47.9)$ & \\
\hline Hospital-acquired & $28(70.0)$ & $197(52.1)$ & \\
\hline Etiology of peritonitis [n (\%)] & & & 0.72 \\
\hline Bowel perforation & $19(47.5)$ & $165(43.6)$ & \\
\hline Anastomotic leakage & $6(15.0)$ & $74(19.6)$ & \\
\hline Biliary pathology & $6(15.0)$ & $44(11.6)$ & \\
\hline Ischemia & $3(7.5)$ & $34(9.0)$ & \\
\hline Abdominal Abscess & $2(5.0)$ & $36(9.5)$ & \\
\hline Pancreatitis & $4(10.0)$ & $18(4.8)$ & \\
\hline Bladder perforation & $0(0.0)$ & $3(0.8)$ & \\
\hline Uterine perforation & $0(0.0)$ & $3(0.8)$ & \\
\hline Vesical perforation & $0(0.0)$ & $4(1.1)$ & \\
\hline Location of the peritonitis ${ }^{\dagger}[n(\%)]$ & & & 0.75 \\
\hline Colon/rectum & $20(50.0)$ & $154(40.7)$ & \\
\hline Small bowel & $7(17.5)$ & $72(19.0)$ & \\
\hline Biliary pathology & $5(12.5)$ & $60(15.9)$ & \\
\hline Stomach and duodenum & $1(2.5)$ & $31(8.2)$ & \\
\hline Pancreas & $4(10.0)$ & $23(6.1)$ & \\
\hline Appendix & $2(5.0)$ & $16(4.2)$ & \\
\hline Bladder & $0(0.0)$ & $10(2.6)$ & \\
\hline Various & $1(2.5)$ & $8(2.1)$ & \\
\hline Uterus/fallopian tubes & $0(0.0)$ & $4(1.1)$ & \\
\hline \multicolumn{4}{|l|}{ Clinical score } \\
\hline APACHE II (mean \pm SD) & $15.95 \pm 4.29$ & $13.65 \pm 5.16$ & 0.007 \\
\hline SOFA (mean \pm SD) & $8.10 \pm 2.50$ & $6.22 \pm 2.46$ & $<0.001$ \\
\hline \multicolumn{4}{|l|}{ Postoperative management } \\
\hline Low-dose steroid therapy [n (\%)] & $25(62.5)$ & $97(25.7)$ & $<0.001$ \\
\hline Blood transfusions, units & $3.50 \pm 7.44$ & $2.37 \pm 4.89$ & 0.192 \\
\hline Politransfusion (>10 units) [n (\%)] & $6(15.0)$ & $45(11.9)$ & 0.57 \\
\hline \multicolumn{4}{|l|}{ Mechanical ventilation } \\
\hline Total duration (days \pm SD) & $8.91 \pm 14.49$ & $2.61 \pm 6.19$ & $<0.001$ \\
\hline Patients requiring $>48 \mathrm{~h}[\mathrm{n}(\%)]$ & $19(47.5)$ & $77(20.4)$ & $<0.001$ \\
\hline Time for VAP onset (mean days \pm SD) & $16.8 \pm 15.1$ & - & \\
\hline
\end{tabular}


Table 1 continued

\begin{tabular}{llll}
\hline & VAP patients $(\boldsymbol{n}=\mathbf{4 0})$ & Non-VAP patients $(\boldsymbol{n}=\mathbf{3 7 8})$ & \\
\hline Clinical outcome & & $3.0(1.0-7.0)$ & $<0.001$ \\
Stay at ICU, median days (IQR) & $9.0(7.0-30.0)$ & $20.0(11.0-34.0)$ & $<0.001$ \\
Total stay at the hospital, median days (IQR) & $45.0(29.0-61.0)$ & $76(20.1)$ & 0.69 \\
Mortality after 30 days $[n(\%)]$ & $7(17.5)$ & $96(25.4)$ & 0.008 \\
Mortality after 90 days $[n(\%)]$ & $18(47.5)$ &
\end{tabular}

VAP ventilator-associated pneumonia, SD standard deviation, APACHE II Acute Physiology and Chronic Health Evaluation II, SOFA Sepsis-Related Organ Failure Assessment, ICU intensive care unit, IQR interquartile range

+ In some patients, the infection extended into more than one location

Table 2 Microorganisms isolated from lungs and peritoneal fluid associated with VAP in patients with secondary peritonitis

\begin{tabular}{|c|c|c|c|c|}
\hline & \multicolumn{2}{|l|}{ Lungs } & \multicolumn{2}{|l|}{ Peritoneal fluid } \\
\hline & VAP patients $(n=40)$ & Non-VAP patients $(n=378)$ & VAP patients $(n=40)$ & Non-VAP patients $(n=378)$ \\
\hline \multicolumn{5}{|l|}{ Gram-positive cocci } \\
\hline $\begin{array}{l}\text { Methicillin susceptible } \\
\text { Staphylococcus aureus }\end{array}$ & $6(15.0)$ & $0(0.0)$ & $1(2.5)$ & $8(2.1)$ \\
\hline $\begin{array}{l}\text { Methicillin-resistant } \\
\text { Staphylococcus aureus }\end{array}$ & $2(5.0)$ & $0(0.0)$ & $0(0.0)$ & $2(0.5)$ \\
\hline Staphylococcus epidermidis & $0(0.0)$ & $0(0.0)$ & $7(17.5)$ & $26(6.9)$ \\
\hline Other Staphylococcus spp. & $2(5.0)$ & $0(0.0)$ & $0(0.0)$ & $16(4.2)$ \\
\hline Streptococcus spp. & $0(0.0)$ & $0(0.0)$ & $4(10.0)$ & $33(8.7)$ \\
\hline Enterococcus spp. & $1(2.5)$ & $0(0.0)$ & $15(37.5)$ & $91(24.1)$ \\
\hline Other & $0(0.0)$ & $0(0.0)$ & $4(10.0)$ & $10(2.6)$ \\
\hline \multicolumn{5}{|l|}{ Gram-negative bacilli } \\
\hline Klebsiella spp. & $7(17.5)$ & $0(0.0)$ & $10(25.0)$ & $27(7.1)$ \\
\hline Enterobacter spp. & $1(2.5)$ & $0(0.0)$ & $6(15.0)$ & $25(6.6)$ \\
\hline Escherichia coli & $4(10.0)$ & $0(0.0)$ & $14(35.0)$ & $108(28.6)$ \\
\hline Pseudomonas aeruginosa & $7(17.5)$ & $0(0.0)$ & $6(15.0)$ & $3(0.8)$ \\
\hline Acinetobacter spp. & $18(45.0)$ & $1(0.3)$ & $2(5.0)$ & $5(1.3)$ \\
\hline Other Enterobacteriaceae & $2(5.0)$ & $0(0.0)$ & $0(0.0)$ & $8(2.1)$ \\
\hline Anaerobes & $1(2.5)$ & $1(0.3)$ & $10(25.0)$ & $104(27.5)$ \\
\hline
\end{tabular}

Percentages may sum more than $100 \%$ because more than one pathogen could have been found in an individual patient

non-VAP patients $(\log$ rank $=5.289 ; p=0.021$; Fig. 1$)$, indicating higher values for non-VAP patients. Both survival curves diverged after the day 40th of admission in the ICU.

\section{Factors associated with in-hospital mortality and development of VAP}

By classifying patients in survivors $(n=304,72.7 \%)$ and nonsurvivors $(n=114,27.3 \%)$, the univariate analysis demonstrated that in-hospital mortality was significantly associated with 19 demographic or clinical variables (Table 3). The logistic regression model indicated that independent factors associated with 30-day in-hospital mortality were age (OR 1.038; CI 95 \% 0.003-1.013; $p=0.003$ ), SOFA (OR 1.329, CI $95 \%$ 0.0001-1.171; $p<0.001$ ), and severe sepsis/septic shock (OR 3.105; CI $95 \% 0.013-1.271 ; p=0.013)$. Stepwise logistic regression model to identify independent factors associated with inhospital mortality at $30,30-90$, and 90 days in patients with secondary peritonitis is given in Table 4. Independent factors associated with 30- to 90-day in-hospital mortality were SOFA (OR 1.373, CI $95 \%$ 0.0001-1.151; $p<0.001$ ), and VAP (OR 3.777, CI $95 \%$ 0.006-1.475; $p=0.006$ ). Factors associated with 90-day in-hospital mortality were age (OR 1.036; CI $95 \% 0.002-1.013$; $p=0.002$ ), SOFA (OR, 1.247, CI $95 \% 0.006-1.065$; $p=0.006$ ), creatinine (OR 1.351; CI $95 \% 0.042-1.011$; $p=0.042$ ), and severe sepsis/septic shock (OR 2.967; 


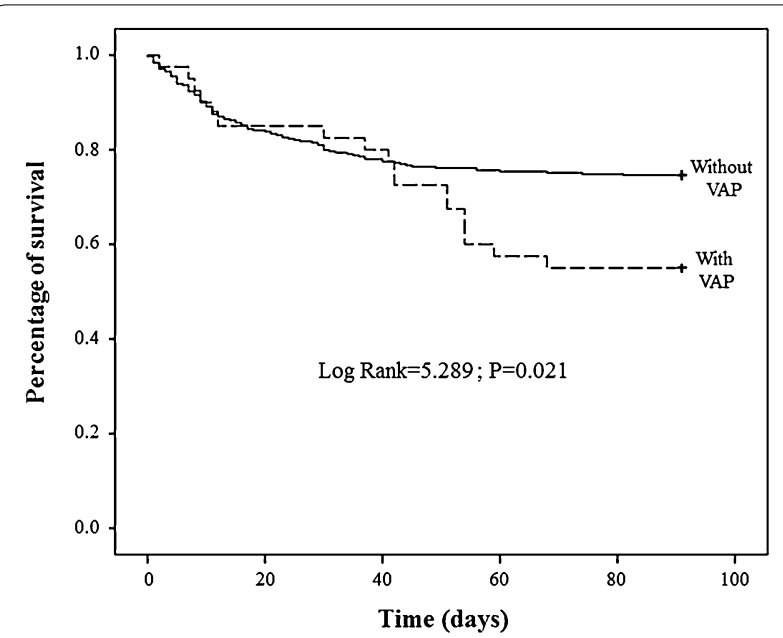

Fig. 1 Kaplan-Meier analysis showing the percentage of survival between patients with and without ventilator-associated pneumonia

CI $95 \%$ 0.004-1.402; $p=0.004)$. Finally, independent factors associated with the development of VAP were hospital-acquired peritonitis (OR 2.873; CI $95 \% 1.299$ $6.369 ; p=0.009$ ), SOFA (OR 1.325; CI $95 \% 1.126-1.559$; $p=0.001)$, and requiring $>48 \mathrm{~h}$ of mechanical ventilation (OR 2.359; CI $95 \%$ 1.074-5.181; $p=0.032$ ).

\section{Discussion}

Despite the significant impact of nosocomial infections on morbidity and mortality of patients staying in the ICU, no study over the last 20 years has determined the clinical, epidemiological, and microbiological features of VAP following secondary peritonitis. Therefore, the goal of the present study was to complete and update such lacking information. The most relevant results from our study included: (1) an updated incidence value of VAP of $9.6 \%$; (2) risk factors associated with the development of VAP including hospital-acquired peritonitis, requiring $>48 \mathrm{~h}$ of mechanical ventilation, and SOFA score; (3) mainly late onset of VAP, and caused by multidrug-resistant microorganisms intrinsically different for each condition; (4) the 90-day in-hospital mortality rate of $47.5 \%$ of VAP patients; and (5) independent factors associated with 30to 90-day in-hospital mortality including VAP and SOFA score.

Overall incidence of VAP reported in our study was $9.6 \%$ of patients who underwent surgery due to

Table 3 Significant demographic and clinical variables potentially associated with in-hospital mortality

\begin{tabular}{|c|c|c|c|}
\hline & Nonsurvivors $(n=114)$ & Survivors $(n=304)$ & $P$ value \\
\hline Age (mean years $\pm S D$ ) & $74.69 \pm 10.43$ & $68.38 \pm 13.58$ & 0.006 \\
\hline \multicolumn{4}{|l|}{ Comorbidities [n (\%)] } \\
\hline Chronic renal failure & $21(18.4)$ & $18(5.9)$ & $<0.001$ \\
\hline Acute renal failure, dialysis & $3(2.6)$ & $6(2.0)$ & $<0.001$ \\
\hline Immunosuppression & $11(9.6)$ & $4(1.3)$ & $<0.001$ \\
\hline Postoperative status & & & 0.001 \\
\hline Severe sepsis & $12(10.5)$ & $139(45.7)$ & \\
\hline Septic shock & $100(87.7)$ & $163(53.6)$ & \\
\hline \multicolumn{4}{|l|}{ Biochemical parameters at ICU (mean \pm SD) } \\
\hline Sodium (mEq/L) & $137.64 \pm 6.8$ & $136.05 \pm 4.81$ & $<0.001$ \\
\hline Creatinine (mg/dL) & $2.18 \pm 1.71$ & $1.21 \pm 0.77$ & $<0.001$ \\
\hline Lactate $(\mathrm{mmol} / \mathrm{L})$ & $34.90 \pm 26.16$ & $24.13 \pm 19.28$ & 0.005 \\
\hline Procalcitonin (ng/mL) & $24.48 \pm 36.42$ & $16.27 \pm 30.28$ & 0.043 \\
\hline $\mathrm{HCO}_{3}{ }^{-}(\mathrm{mEq} / \mathrm{L})$ & $20.42 \pm 7.28$ & $21.73 \pm 5.52$ & 0.030 \\
\hline \multicolumn{4}{|l|}{ Postoperative management } \\
\hline Low-dose steroid therapy & $25(21.9)$ & $97(31.9)$ & $<0.001$ \\
\hline Blood transfusions, units & $4.43 \pm 6.90$ & $1.74 \pm 4.16$ & $<0.001$ \\
\hline Politransfusion (>10 units) $[n(\%)]$ & $26(22.8)$ & $25(8.2)$ & $<0.001$ \\
\hline \multicolumn{4}{|l|}{ Mechanical ventilation } \\
\hline Total duration (days \pm SD) & $7.38 \pm 11.70$ & $1.69 \pm 4.48$ & $<0.001$ \\
\hline Patients requiring $>48 \mathrm{~h}[\mathrm{n}(\%)]$ & $50(43.9)$ & $46(15.1)$ & $<0.001$ \\
\hline \multicolumn{4}{|l|}{ Clinical outcome } \\
\hline Stay at ICU, median days (IQR) & $8.0(3.8-14.3)$ & $3.0(1.0-6.0)$ & $<0.001$ \\
\hline Total stay at the hospital, median days (IQR) & $21.0(9.3-43.8)$ & $21.0(12.3-35.0)$ & 0.004 \\
\hline VAP & $18(15.8)$ & $22(7.2)$ & 0.008 \\
\hline
\end{tabular}

$S D$ standard deviation, $I C U$ intensive care unit, $\mathrm{HCO}_{3}{ }^{-}$bicarbonate, VAP ventilator-associated pneumonia, IQR interquartile range 
Table 4 Logistic regression models to identify factors associated with in-hospital mortality and with the development of VAP

\begin{tabular}{|c|c|c|c|}
\hline & OR & $95 \% \mathrm{Cl}$ & $P$ value \\
\hline \multicolumn{4}{|l|}{ In-hospital mortality } \\
\hline \multicolumn{4}{|l|}{ 30-day in-hospital mortality } \\
\hline Age (years) & 1.038 & $1.013-1.064$ & 0.003 \\
\hline SOFA score & 1.329 & $1.171-1.510$ & $<0.001$ \\
\hline Severe sepsis/septic shock & 3.105 & $1.271-7.588$ & 0.013 \\
\hline \multicolumn{4}{|l|}{ 30- to 90-day in-hospital mortality } \\
\hline SOFA score & 1.373 & $1.151-1.637$ & $<0.001$ \\
\hline VAP & 3.777 & $1.475-9.671$ & 0.006 \\
\hline \multicolumn{4}{|l|}{ 90-day in-hospital mortality } \\
\hline Age (years) & 1.036 & $1.013-1.060$ & 0.002 \\
\hline SOFA score & 1.247 & $1.065-1.461$ & 0.006 \\
\hline Creatinine (mg/dL) & 1.351 & $1.011-1.805$ & 0.042 \\
\hline Severe sepsis/septic shock & 2.967 & $1.402-6.278$ & 0.004 \\
\hline \multicolumn{4}{|l|}{ Development of VAP } \\
\hline Hospital-acquired peritonitis & 2.873 & $1.299-6.369$ & 0.009 \\
\hline SOFA score & 1.325 & $1.126-1.559$ & 0.001 \\
\hline $\begin{array}{l}\text { Requiring }>48 \text { h of mechanical } \\
\text { ventilation }\end{array}$ & 2.359 & $1.074-5.181$ & 0.032 \\
\hline
\end{tabular}

OR odds ratio, $\mathrm{Cl}$ confidence interval, SOFA Sepsis-Related Organ Failure Assessment, VAP ventilator-associated pneumonia

peritonitis, a value significantly lower than previous studies, ranging between 20 and $30 \%$ [14, 15]. A possible explanation may derive from the fact that, in our study, VAP included both hospital- and community-acquired cases; however, previous studies only included hospitalacquired cases, which are associated with higher incidence rates. Moreover, the reduction in the impact of VAP over the years may be a result of the implementation of effective preventive strategies in the ICU, such as the Spanish national VAP prevention bundle called "zero VAP," based on good general practices for control of the infection and pathogenic-tailored strategies [23, 24]. The International Nosocomial Infection Control Consortium reported a decrease in incidence from 15 to $8 \%$ in a surveillance study conducted from 2004 to 2009 [25, 26].

There are many factors potentially associated with the development of VAP, including preexisting medical conditions in the patient (such as immunosuppression or chronic obstructive lung disease), body position, level of consciousness, nasotracheal intubation, duration of the mechanical ventilation, ventilator circuit-related factors, enteral nutrition, or personnel-related factors (such as inadequate hand hygiene or change in gloves between patients) [12, 27, 28]. In our study, hospital-acquired peritonitis, requiring $>48 \mathrm{~h}$ of mechanical ventilation, and SOFA score were independent factors for VAP development. The duration of ventilation has been positively correlated with the development of VAP, although this potential risk seems not to be constant over the time [12]. Specifically, the risk of VAP has been estimated in $3 \%$ per day during the first week of mechanical ventilation, $2 \%$ in the second week, and $1 \%$ in the subsequent weeks [27]. A high SOFA score at admission in the ICU has been associated with mortality in VAP patients [29]; for this reason, a high score in multiple organ dysfunction, concomitant with a probably immunosuppression status and/or other underlying medical conditions, may be a cause for the development of such opportunistic infection. Similarly, hospital-acquired peritonitis is associated with microorganisms presenting antibiotic resistance, poor outcomes, and longer stays in the hospital, compared with community-acquired peritonitis, which may explain its correlation with the development of VAP [2].

The onset of VAP was late in the majority of patients. More than $90 \%$ of cases of VAP occur within the first 10 days of the intubation [30]. VAP was also developed about 16.8 days after the initiation of the peritonitis. A high percentage of the microorganisms responsible of VAP were multidrug resistant (62.5\%). Regarding the antibiogram, almost half of patients $(55.0 \%)$ received an adequate treatment. The low number of patients receiving adequate antibiotic treatment may be a consequence of: (1) the late onset of pneumonia $(16.8 \pm 15.1$ days $)$ since the initiation of the peritonitis. At this time, patients had received other antibiotic treatments for the peritonitis. (2) the peritonitis was the primary target of the antibiotic treatment; VAP was not so. It has been demonstrated that patients who receive inadequate empiric antibiotic treatment have longer hospital stays, higher rates of abscesses, and mortality [31]. For this reason, attention should be given to the antibiogram of each respective center, selecting adequate antibiotics taken into account potential multidrug-resistant microorganisms [1]. The high rate of multidrug resistance found in our study may be correlated with the higher proportion of patients presenting late-onset VAP. In general, etiological microorganisms responsible for the peritonitis were different than for VAP, which is consistent with previous studies [6].

According to published studies, mortality rates attributable to VAP range between 53 and $75 \%$ [14, 15]. Since clinical outcomes depend on the length of the stay in the ICU, one goal of our study was to investigate differences in in-hospital mortality at different endpoints $(30,30-90$, and 90 days). VAP patients showed a significant higher mortality rate and longer hospital stay than non-VAP. The 90-day mortality was $47.5 \%$ of VAP patients, a value slightly lower than previous studies. Similar to the incidence, there is a decreasing tendency in the mortality rate as a result of the implementation of preventive strategies [22, 25]. In our 
study, the mortality rate was actually quite high, even in the non-VAP cohort, for secondary peritonitis. The recent multicenter STOP-IT trial has reported a mortality rate of $1.2 \%$ for patients with complicated intra-abdominal infection [32]. Although this study cohort did have a much higher rate of septic shock and severe sepsis than that our study, most recent severe sepsis and septic shock studies have reported mortality rates of approximately $25 \%$. Risk factors associated with in-hospital mortality included VAP and SOFA score, although the univariate analysis revealed both VAP and stay at ICU as significant risk factors associated with mortality. VAP was only significant for 30- to 90-day in-hospital mortality. According to the literature, the development of VAP is associated with the percentage of nonsurvivors and survivors in a rate 2:1. It is interesting to note that Kaplan-Meier curves showed a significant divergence in survival likelihood since approximately the day 40th after admission in the ICU. Among the extensive studies evaluating the risk factors associated with worse outcomes and mortality for secondary peritonitis [31, 33-35], none of them have included VAP in their analyses. One possible reason to omit it might derive from the fact that VAP is intrinsically associated with the stay in the ICU, whatever the underlying condition of the patient. Nevertheless, results of our study highlight the importance of including VAP as a factor involved in the 30- to 90-day in-hospital mortality of patient with secondary peritonitis. Our present study had some limitations. One of them was that the study was performed in a single center. A multicenter study might have strengthen results obtained in the study and have reduced factors intrinsically associated with the center, such as the empiric antibiotic treatment or the spectrum of nosocomial pathogenic microorganisms. Another limitation of the study was the low number of patients developing VAP (40). Although similar to the sample size of the literature, a large cohort of patients might also have strengthen our results and diminish interindividual differences.

\section{Conclusion}

In light of the impact on morbidity and mortality in the ICU, more attention should be given to the concurrent features among VAP and secondary peritonitis. Additional prospective studies, involving large cohort of patients, are required to corroborate these results.

\footnotetext{
Author details

${ }^{1}$ Anaesthesiology and Surgical Critical Care Department, Hospital Clínico Universitario de Valladolid, Avenida Ramón y Cajal, 3, 47005 Valladolid, Spain. ${ }^{2}$ Group of Biomedical Research in Critical Care Medicine (BioCritic), Hospital Clínico Universitario de Valladolid, Valladolid, Spain. ${ }^{3}$ Department of Pharmacology and Therapeutics, Faculty of Medicine, University of Valladolid, Valladolid, Spain. ${ }^{4}$ Department of Cardiovascular Surgery, Hospital Universitario de La Princesa, Madrid, Spain. ${ }^{5}$ Department of Microbiology, Faculty of Medicine, University of Valladolid, Valladolid, Spain. ${ }^{6}$ Investigación Médica en Infección e Inmunidad (IMI), Hospital Clínico Universitario de Valladolid-IECSCYL, Valladolid, Spain.
}

\section{Acknowledgements}

Authors would like to express thankfulness to the nurses from our ICU. Authors would also like to thank to Patricia Ortega and Pablo Vivanco (PhD, Meisys) for helping in the elaboration of the manuscript.

\section{Competing interests}

The authors declare that they have no competing interests.

\section{Disclosure of funding}

This work was supported in part by a grant from the Gerencia de Salud, Consejería de Sanidad, Junta de Castilla y León (GRS 773/A/13) and the Ministry of Health (PI15/01451).

Received: 2 December 2015 Accepted: 28 March 2016

Published online: 18 April 2016

\section{References}

1. Lopez N, Kobayashi L, Coimbra R. A comprehensive review of abdominal infections. World J Emerg Surg. 2011;6:7.

2. Eckmann C, Dryden M, Montravers P, Kozlov R, Sganga G. Antimicrobial treatment of "complicated" intra-abdominal infections and the new IDSA guidelines? A commentary and an alternative European approach according to clinical definitions. Eur J Med Res. 2011;16(3):115-26.

3. Laroche M, Harding G. Primary and secondary peritonitis: an update. Eur J Clin Microbiol Infect Dis. 1998;17(8):542-50.

4. McClean KL, Sheehan GJ, Harding GK. Intraabdominal infection: a review. Clin Infect Dis. 1994;19(1):100-16.

5. Gauzit R, Péan Y, Barth X, Mistretta F, Lalaude O, Top Study Team. Epidemiology, management, and prognosis of secondary non-postoperative peritonitis: a French prospective observational multicenter study. Surg Infect (Larchmt). 2009;10(2):119-27.

6. Jang JY, Lee SH, Shim H, Choi JY, Yong D, Lee JG. Epidemiology and microbiology of secondary peritonitis caused by viscus perforation: a singlecenter retrospective study. Surg Infect (Larchmt). 2015;16(4):436-42.

7. Koenig SM, Truwit JD. Ventilator-associated pneumonia: diagnosis, treatment, and prevention. Clin Microbiol Rev. 2006;19(4):637-57.

8. American Thoracic Society. Infectious Diseases Society of America. Guidelines for the management of adults with hospital-acquired, ventilatorassociated, and healthcare-associated pneumonia. Am J Respir Crit Care Med. 2005;171(4):388.

9. Tamayo E, Álvarez FJ, Martínez-Rafael B, Bustamante J, Bermejo-Martin JF, Fierro I, et al. Ventilator-associated pneumonia is an important risk factor for mortality after major cardiac surgery. J Crit Care. 2012;27(1):18-25.

10. Kappstein I, Schulgen G, Beyer U, Geiger K, Schumacher M, Daschner FD. Prolongation of hospital stay and extra costs due to ventilator-associated pneumonia in an intensive care unit. Eur J Clin Microbiol Infect Dis. 1992;11(6):504-8.

11. Heyland DK, Cook DJ, Griffith L, Keenan SP, Brun-Buisson C. The attributable morbidity and mortality of ventilator-associated pneumonia in the critically ill patient. Am J Respir Crit Care Med. 1999;159(4):1249-56.

12. Bonten MJ, Kollef MH, Hall JB. Risk factors for ventilator-associated pneumonia: from epidemiology to patient management. Clin Infect Dis. 2004;38(8):1 141-9.

13. Safdar N, Dezfulian C, Collard HR, Saint S. Clinical and economic consequences of ventilator associated pneumonia: a systematic review. Crit Care Med. 2005;33(10):2184-93.

14. Richardson JD, DeCamp MM, Garrison RN, Fry DE. Pulmonary infection complicating intra-abdominal sepsis: clinical and experimental observations. Ann Surg. 1982;195(6):732-8.

15. Mustard RA, Bohnen JM, Rosati C, Schouten BD. Pneumonia complicating abdominal sepsis: an independent risk factor for mortality. Arch Surg. 1991;126(2):170-5.

16. Thompson DA, Makary MA, Dorman T, Pronovost PJ. Clinical and economic outcomes of hospital acquired pneumonia in intra-abdominal surgery patients. Ann Surg. 2006;243(4):547-52.

17. Solomkin JS, Mazuski JE, Bradley JS, et al. Diagnosis and management of complicated intra-abdominal infection in adults and children: guidelines by the Surgical Infection Society and the Infectious Diseases Society of America. Clin Infect Dis. 2010;50:133-64. 
18. Marshall JC, Maier RV, Jimenez M, Dellinger EP. Source control in the management of severe sepsis and septic shock: an evidence-based review. Crit Care Med. 2004;32(11):513-26.

19. Ibrahim EH, Ward S, Sherman G, Schaiff R, Fraser VJ, Kollef MH. Experience with a clinical guideline for the treatment of ventilator-associated pneumonia. Crit Care Med. 2001;29(6):1109-15

20. Garner JS, JarvisWR Emori TG, et al. CDC definitions for nosocomial infections. Am J Infect Control. 1988;16(4):128-40.

21. Medford AR, Husain SA, Turki HM, Millar AB. Diagnosis of ventilator-associated pneumonia. J Crit Care. 2009;24(473):e1-6.

22. Luna CM, Blanzaco D, Niederman MS, Matarucco W, Baredes NC, Desmery $P$, et al. Resolution of ventilator-associated pneumonia: prospective evaluation of the clinical pulmonary infection score as an early clinical predictor of outcome. Crit Care Med. 2003;31(3):676-82.

23. Mietto C, Pinciroli R, Patel N, Berra L. Ventilator associated pneumonia: evolving definitions and preventive strategies. Respir Care 2013;58(6):990-1007.

24. Lerma FA, García MS, Lorente L, Gordo F, Añón JM, Álvarez J, et al. Guidelines for the prevention of ventilator-associated pneumonia and their implementation. The Spanish "Zero-VAP" bundle. Med Intensiva. 2014;38(4):226-36.

25. Rosenthal VD, Bijie H, Maki DG, Mehta Y, Apisarnthanarak A, Medeiros EA, et al. International Nosocomial Infection Control Consortium (INICC) report, data summary of 36 countries, for 2004-2009. Am J Infect Control. 2012;40(5):396-407

26. Lorente L, Blot S, Rello J. Evidence on measures for the prevention of ventilator-associated pneumonia. Eur Respir J. 2007;30(6):1193-207.

27. Augustyn B. Ventilator-associated pneumonia: risk factors and prevention. Crit Care Nurse. 2007:27(4):32-9.
28. Cook DJ, Walter SD, Cook RJ, Griffith LE, Guyatt GH, Leasa D, et al. Incidence of and risk factors for ventilator-associated pneumonia in critically ill patients. Ann Intern Med. 1998;129(6):433-40.

29. Boeck L, Eggimann P, Smyrnios N, Pargger $H$, Thakkar N, Siegemund $M$, et al. The Sequential Organ Failure Assessment score and copeptin for predicting survival in ventilator-associated pneumonia. J Crit Care. 2012;27(5):523.e1-29.

30. Koulenti D, Lisboa T, Brun-Buisson C, Krueger W, Macor A, Sole-Violan J, et al. Spectrum of practice in the diagnosis of nosocomial pneumonia in patients requiring mechanical ventilation in European intensive care units. Crit Care Med. 2009:37(8):2360-8.

31. Montravers P, Gauzit R, Muller C, Marmuse JP, Fichelle A, Desmonts JM. Emergence of antibiotic-resistant bacteria in cases of peritonitis after intraabdominal surgery affects the efficacy of empirical antimicrobial therapy. Clin Infect Dis. 1996;23(3):486-94.

32. Sawyer RG, Claridge JA, Nathens AB, Rotstein OD, Duane TM, Evans HL, et al. Trial of short-course antimicrobial therapy for intraabdominal infection. N Engl J Med. 2015:372(21):1996-2005.

33. Mulier S, Penninckx F, Verwaest C, Filez L, Aerts R, Fieuws S, Lauwers P. Factors affecting mortality in generalized postoperative peritonitis: multivariate analysis in 96 patients. World J Surg. 2003;27(4):379-84.

34. Riché FC, Dray X, Laisné MJ, Matéo J, Raskine L, Sanson-Le Pors MJ, et al. Factors associated with septic shock and mortality in generalized peritonitis: comparison between community-acquired and postoperative peritonitis. Crit Care. 2009;13(3):99.

35. Inui T, Haridas M, Claridge JA, Malangoni MA. Mortality for intra-abdominal infection is associated with intrinsic risk factors rather than the source of infection. Surgery. 2009;146(4):654-62.

\section{Submit your manuscript to a SpringerOpen ${ }^{\odot}$ journal and benefit from:}

- Convenient online submission

- Rigorous peer review

Immediate publication on acceptance

- Open access: articles freely available online

- High visibility within the field

- Retaining the copyright to your article

Submit your next manuscript at springeropen.com 